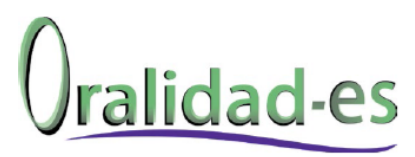

\title{
Mujeres modernas. El lucir y el comunicar en la Colombia del siglo XX
}

\section{Modern Women. Shining and communicating in the $20^{\text {th }}$ century in Colombia}

Ángela Ramos-López

aramosl@poligran.edu.co

Politécnico Grancolombiano, Colombia.

Maria Isabel Zapata-Villamil

mizapata@javeriana.edu.co

Pontificia Universidad Javeriana, Colombia

Ramos-López, Á. y Zapata-Villamil, M. I. (2020). Mujeres modernas. El lucir y el comunicar en la Colombia del siglo XX. Oralidad-es, 6, 1-18. https://revistaoralidad-es.com/index.php/ro-es/article/view/120/130

Fecha de recepción: 30 de septiembre de 2020 / Fecha de aceptación: 23 de diciembre de 2020 


\section{Resumen}

En este artículo partiremos del concepto de género y su relación con la definición y construcción cultural que se da de este a partir de lo comunicativo y expresivo que implica. En este sentido el problema de la comunicación nos interesa no solo porque nuestras fuentes están principalmente en los medios, sino porque la representación y el género se construyen desde lo comunicativo. Nuestra pregunta guía es cómo se han constituido las adscripciones sobre la construcción de lo femenino durante el periodo de 1886 a 1945, a través de la historia cultural y la cultura visual como ejes centrales del análisis de las imágenes de los avisos publicitarios y los artículos de las revistas de la época. Por consiguiente, este artículo tiene el propósito de exponer cómo a las mujeres se le imponían modas, desde vestidos, perfumes, peinados hasta maquillajes. Detrás de estos elementos estaban estilos de vida y comportamientos en los que la sociedad centraba lo que se pensaba significaba ser mujer, enfocándola principalmente en agradar y complacer al hombre.

\section{Palabras Clave}

Moda; género; comunicación; cultura visual; historia cultural

\section{Abstract}

Abstract: In this article we will start from the concept of gender and its relationship with the definition and cultural construction that occurs of it from the communicative and expressive. In this sense, the problem of communication interests us not only because our sources are mainly in the media, but also because representation and gender are constructed from the communicative. Our guiding question is how the ascriptions on the construction of the feminine during the period from 1886 to 1945 have been constituted through cultural history and visual culture as central axes of the analysis of the images of the advertisements and the articles of the magazines of the time. Therefore, this article is intended to expose how fashions were imposed on women, from dresses, perfumes, hairstyles to makeup; Behind those were lifestyles and behaviors in which society created what was mean to be a woman, focusing mainly on pleasing and satisfying men.

Keywords

Fashion; Gender; Communication; Visual Culture and Cultural History 


\section{Concepto de género desde el cual partimos}

Las definiciones de género empiezan a aparecer en las Ciencias Sociales a inicios del siglo XX, cuando Margaret Mead, en su texto Sexo y temperamento de 1935, afirma que los llamados rasgos de personalidad, tanto femeninos como masculinos, eran adjudicados de manera arbitraria y no se relacionaban con la lógica sexual. Adicionalmente, muchas de las discusiones feministas, al utilizar el concepto de género, se oponían a que la biología era un origen y un destino.

Los estudios sobre el género se han dedicado al análisis de los contextos sociales y culturales, desde los cuales se generan las condiciones de posibilidad de las relaciones jerárquicas entre hombres y mujeres y, también, la pregunta por las posibilidades de transformación de estas relaciones. Elemento que nos interesa particularmente para exponer en este artículo.

La propuesta sobre la diferencia entre sexo y género hizo que, tradicionalmente, las investigaciones centradas en el sexo se hicieran desde las Ciencias Biomédicas, mientras que las que tomaban el género como categoría se insertaban en las Ciencias Sociales. En las últimas décadas, la Teoría Queer abrió un debate frente a estos planteamientos, al proponer que la distancia entre sexo y género no es tajante, y que el sexo es siempre construido a partir del género, es decir, que son la cultura y el lenguaje los que hacen inteligible lo biológico. En este sentido, el género y el sexo son el resultado de la recepción de significados culturales, que están siempre abiertos a cambios e innovación.

Asimismo, Judith Butler propone la performatividad del género, planteando que la identidad, la orientación sexual y la expresión del género son el resultado de una construcción social, histórica y cultural, desmontando la idea de los roles de género como esenciales o inscritos dentro de la naturaleza Humana (Duque y Butler, 2010, pp. 85-95). Siguiendo esta línea de ideas, en su texto The Mistery of sex, Mary Ryan plantea que los significados de los conceptos masculino y femenino, referidos al sexo, también variaron a lo largo de la historia. En los últimos años se han hecho un sin número de objeciones a la distinción tajante entre sexo y género, las cuales se ven expresadas, entre otros, en los desarrollos de historiadores de la ciencia como Thomas Laqueur, que entran en el debate para mostrar desde archivos históricos la construcción social del sexo y, en consecuencia, desmontar la diferencia tajante entre sexo y género.

En el campo de la historia, la categoría de género ha sido fuertemente asumida por Joan Scott. En el número de diciembre de 1985 de la American Historical Review, esta autora propone, en el artículo El género: una categoría útil para el análisis histórico, que desde la investigación feminista se pueden transformar los trabajos históricos para estudiar la forma cómo opera el género en las relaciones sociales y explorar los significados atribuidos a las diferencias entre sexos, desde los que se expresan y legitiman relaciones de poder.

Desde esta posición interdisciplinaria sobre el género, el presente documento se centrará en una aproximación a la historia de la representación de las mujeres en Colombia, que descansa en la pregunta sobre cómo se han constituido las adscripciones sobre la construcción de lo femenino en el periodo de 1886 a 1945 . Esto desde las variaciones que ha experimentado la sociedad colombiana en relación con la construcción de lo femenino desde las relaciones establecidas entre mujeres y hombres, y su contexto. A su vez, nos interesa indagar los modos de comunicar a través de las imágenes textuales y visuales una interpretación de las lecturas que existen del cuerpo femenino y su relación con la identidad y las maneras de ver y ser visto. 


\section{Metodología}

Nuestras fuentes primarias fueron las imágenes a las que tuvimos acceso gracias a la Revista Cromos, Fantoches y la Exposición del Museo Nacional, El Museo en el museo, un lugar entre el XIX y el XX (13 de abril al 24 de junio de 2018). Para analizarlas, nos acercamos a ellas desde los conceptos de representaciones y cultura visual. En primera instancia, la representación la vimos como un volver a mostrar algo que está ausente. Así, las imágenes nos volvían a mostrar, exhibían, intensificaban, redoblaban una nueva presencia. Es decir, en palabras de Louis Marin, con el prefijo RE no se hace referencia a un valor de sustitución, sino de intensidad. Es el presentarse como representante de algo. Entonces, la representación contiene las virtudes para que los cuerpos que la miran se remiren en el efecto y sentido de su representación. Es así como lo que se muestra no está tal cual es, sino con énfasis en lo que se quiere resaltar de los cuerpos.

Nuestro segundo punto de atención, con respecto a la cultura visual, proviene del Acto del Ver. Acudiremos, así, al estudio de la imagen centrado tanto en la forma en que se constituye la representación como en la indagación por los sentidos y significados que se le otorgan a los Actos de Ver en el mostrarse y el observar desde su carácter cultural.

Ahora bien, la fotografía fue un instrumento para construir un proyecto civilizatorio de la clase dirigente. Por medio de esta se mostró a la élite y su proyecto de modernidad, constituyéndose como la imagen de un país en proceso de industrialización, con la construcción de carreteras, vías férreas y la aparición de una incipiente clase media. Pero, por otro lado, hay una parte de la sociedad que aún lucha por permanecer en la tradición católica del siglo XIX. Este escenario lleno de matices hace que las imágenes de los humildes empiecen a aparecer al lado de imágenes sobre obras de progreso y la presencia de mujeres en su papel de damas distinguidas.
Esta diversidad de fotografías mostraba una Colombia que en la realidad, internamente, estaba llena de contradicciones. Pero, como era de esperarse, también apareció un nuevo protagonista: la masa. Uno de los representantes más destacados de esta época fue Luis B Ramos, quien, luego de viajar a Francia, retornó al país y en la década de los 30 fue el encargado de dar testimonio en la revista Cromos de esa Colombia que emergía luego del proceso de modernización con un gran número de contradicciones.

Reconociendo lo anterior, en un último punto, buscamos en las imágenes esos elementos que dieran cuenta de los valores culturales propios de la modernidad. Ello dado que al lado de las obras de progreso, productos prometedores y mujeres bellas estaban los campesinos, los ciudadanos pobres, los trabajadores aún inconformes, etc. Esos son los elementos que esperamos encontrar, expresados a partir del cuerpo y la moda, y registrados por medio de las imágenes.

\section{Representación de la mujer en Colombia en el paso del siglo XIX al XX}

El proceso de modernización colombiano inició a finales del siglo XIX y generó fuertes conflictos en las relaciones de género. Desde este momento hasta la década de los 50 se dieron fuertes vaivenes para que las mujeres alcanzaran la ciudadanía y tuvieran derecho al voto. El cuerpo y la forma de disciplinarlo y modelarlo fueron elementos desde los cuales se evidenciaban la difusión de los valores de la cultura moderna en Colombia. La instauración de la industria, la nueva concepción de tiempo homogéneo medido por el reloj, el valor de lo material, el consumo y la importancia del trabajo asalariado, entre otros, fueron circunstancias que hicieron que la moda y el cuerpo expresaran las tensiones que se 
producían en las concepciones de género en la sociedad. En este aparte, veremos cuáles fueron los hechos más importantes que acaecieron durante el período y cómo influenciaron la vida de las mujeres.

Las revoluciones políticas, desde la Revolución francesa y pasando por la Independencia norteamericana, fueron atravesadas por tensiones y reacomodaciones en las relaciones de género. Por ejemplo, la Revolución Francesa tuvo participación de las mujeres, pero la reivindicación de sus derechos y la consecución de la igualdad fue un proceso de largos vaivenes, devenires, reacomodaciones, largas disputas y conflictos. A pesar de que 22 mujeres participaron en los enfrentamientos bélicos de la Revolución Francesa, vistiéndose de hombres combatientes, no podemos olvidar las imágenes peyorativas de María Antonieta, en las que se le veía como símbolo de los males de la monarquía. En palabras de Sonya Rose (2012), al final, en los procesos revolucionarios no se abrió la puerta a que las mujeres fueran aceptadas como actores en el escenario de la política nacional. Entonces, aunque en 1791 se publicaron los derechos de la mujer y la ciudadana, en 1799 estos derechos quedarían totalmente limitados bajo el régimen de Napoleón. La lucha por el sufragio femenino fue ardua, por ejemplo, en EE. UU. se logró en 1920 y en Inglaterra en 1928.

De acuerdo con la activista rusa Emma Goldman, el voto no era precisamente el fin de su lucha, esta tenía como objetivo precisamente librarse de la sujeción en todos los espacios de su vida, principalmente en el hogar donde más injusticias vivían. Esto hizo que el proceso de conquista de nuevos espacios para la mujer se diera por medio de un largo proceso, en el que los ires y venires al final nos llevarían a una sociedad que promoviera la participación amplia de las mujeres en lugares de decisión. Dentro de este largo proceso el cambio de siglo sería un periodo de gran importancia debido a las complejas transformaciones que se vivirían en Colombia.
Entre 1886 y 1945 se acrecienta la intervención económica y política de los norteamericanos en América Latina. Es la etapa que contempla el período entre guerras y consolida la influencia norteamericana en el mundo. Esto hizo que se comenzara a desarrollar una dependencia económica, tecnológica y cultural muy estrecha entre Estados Unidos y Colombia (Lombana, 2018). Esta situación generó una intensificación de la importación de mercancías y modelos norteamericanos de adiestramiento de los comportamientos, al lado de los europeos que ya se venían incorporando de tiempo atrás, por medio de métodos propios de la sociedad de consumo, tales como avisos publicitarios en revistas de amplios tirajes que cada vez más contribuían a generar una cultura visual de masas. Desde estas dinámicas a las mujeres se les iban imponiendo modas en cuanto a vestidos, perfumes, peinados y maquillajes, detrás de lo que se ocultaban unos estilos de vida y comportamientos de lo que significaba ser femenina, centrándose en el agradar y complacer al hombre (Lombana, 2018).

Entonces, durante finales del siglo XIX y la primera mitad del siglo XX se desarrolló una nueva construcción de feminidad. Para entender estos procesos que se vieron reflejados en las figuraciones de la mujer que se publicaron en la prensa, es necesario ver todo el tejido complejo que confluyó en ella. Debemos considerar, entonces, la aparición de la chica moderna, esa chica It (como se le llamó en la época) que siempre estaba en búsqueda de la novedad y el cambio, lo cual se logró luego de un proceso complejo de intercambios entre lo propio, lo local y los elementos que llegaban de otros lugares.

En este proceso fueron de suma importancia las publicaciones periódicas, en las cuales observamos que las imágenes de la chica moderna no aparecían de una manera unívoca. Estas publicaciones fueron parte de discusiones que se gestaban en medio de la agenda mediática, proceso propio de la negociación que ocurría al ponerse en juego las representaciones que se querían imponer 
como modelos a seguir. Dichas discusiones no fueron solamente objeto de artículos y sermones en iglesias, en medio de la discusión también se publicaron fotografías, ilustraciones y anuncios publicitarios, tanto nacionales como extranjeros, que evidenciaban cómo el problema de la discusión sobre la construcción de una nueva valoración de lo que era la mujer atravesaba su relación con la moda, los peinados, los zapatos, el maquillaje y la expresión corporal.

Unido a la novedad, uno de los valores fundamentales que conllevó la modernidad fue el del movimiento. Cuando se tuvo la libertad de trasladarse de un lugar a otro, la posibilidad de mantener y exhibir cuerpos sanos, vitales y dispuestos para el trabajo que requería el proceso de modernización, fueron elementos que empezaron a ser resaltados por estas imágenes que promovían las chicas modernas (Rose, 2012). La chica It que apareció en las revistas colombianas de la época no era exclusiva de nuestro país, apareció, también, en Europa, Asia, Estados Unidos y África subsahariana, pero en cada lugar tenía sus características particulares. En el caso de Colombia la discusión giró fuertemente en relación con la Iglesia católica, la cual en este período luchaba por mantener vigente su lugar central en la dirección y ejecución de la manera de incorporación del país dentro de la modernidad. Este era el papel que había conseguido la Iglesia Católica en Colombia luego de haberse proclamado la constitución de 1886 y de la firma del concordato con el Vaticano en 1887 (Lombana, 2018).

La ciudad fue el puente dentro del movimiento expansivo de la moda. Esta recogió la moda y desde ella se irradió hasta los lugares más apartados, al cabo de cierto tiempo (Rivière, 1977). Entonces, el cuadro idóneo para el nacimiento de tendencias y/o estilos, ocurrió en las ciudades, puesto que eran, y siguen siendo, los núcleos de consumo de gran relevancia.
A medida que el progreso iba avanzando en el país, las mujeres tomaron conciencia de esto, y fueron exigiendo libertad a partir de pequeños procesos que fueron alterando su condición a medida que la sociedad se iba renovando. Tanto así que el pensamiento femenino debía, en cierta medida, modernizarse y, así, poder construir una imagen de una mujer fuerte, libre pensadora y que no fuera discriminada. Esto surgió a través de la moda como un vehículo que comunicaba el deseo de la transgresión de las fronteras limitantes.

La mujer al vincularse al mundo moderno tuvo que enfrentar varios cambios, tanto en ella misma como en su entorno. En efecto, la moda se constituyó como un símbolo de manifestación que progresivamente se transformaba en cambio, tanto en las prendas como en su uso propio. Es así que se consolidó como un vehículo que proponía e imponía al individuo unos determinados valores que producían una identidad cultural y social (San Martin, 2009).

Como consecuencia, el acto de vestir era individual y personal, pues se trataba de preparar el cuerpo para el mundo social, hacerlo apropiado, aceptable, respetable y, quizás, deseable (Entwistle, 2002). Asimismo, el vestido generaba y creaba una experiencia con el cuerpo, pues, ante todo, somos cuerpos humanos vestidos (Entwistle, 2002) interactuando alrededor de un entorno social. Por lo tanto, se constituía como un acto íntimo experiencial, que el cuerpo-vestido iba creando a raíz de la relación sinérgica existente entre el cuerpo, las prendas y la cultura del momento.

El cuerpo-vestido y el yo, como individuo, siempre serían vistos, juzgados y percibidos por el entorno social y cultural, a pesar de que la experiencia del vestir era un acto subjetivo de cuidar al propio cuerpo. Además, era un objeto de conciencia entre el cuerpo y el yo (Entwistle, 2002), que se encontraban de alguna manera ligados a la sociedad en una época determina- 
da por medio del vestido. Siendo este último elemento uno de los detonantes que hacía parte de la transformación del género femenino y de la historia per se.

\section{Figura 1.}

Fotografía de la Sra. Magdalena Fety de Sáenz.

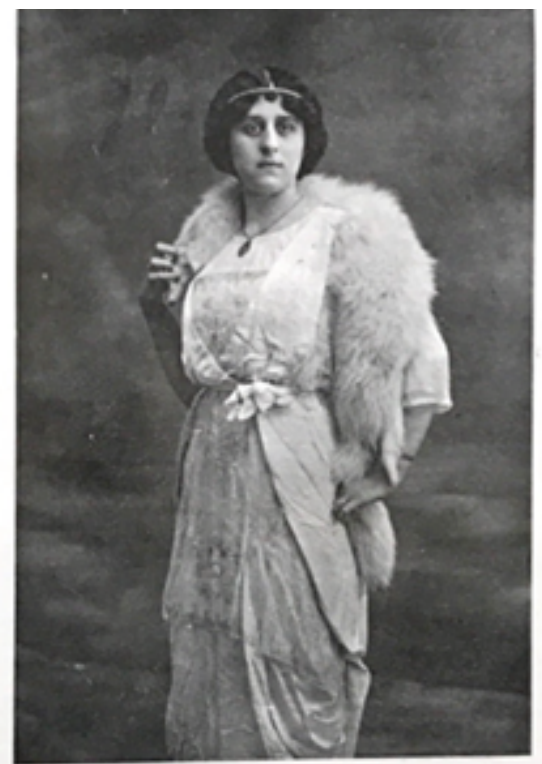

\section{Sra. Magdalena Fety de Sáenz (De Bogotá).}

Fuente: Sección Álbum Cromos. No.173. Vol. VIII. Agosto 2, 1919.

La figura femenina rompió con los esquemas. $\mathrm{Si}$ bien es cierto que el estilo neoimperio y el orientalismo fueron levemente aceptados dentro de las sociedades burguesas, al llegar la funcionalidad de la silueta al cuerpo femenino se transgredió el lenguaje semiótico del vestido y del cuerpo. Así, la Primera Guerra Mundial trajo consigo una serie de cambios, ya que la ropa uniforme sería una inspiración para el vestido socio (Soral, 1998). Entonces, el traje funcional haría que Norteamérica posesionara el Ready-To-Wear y que diseñadoras como Coco Chanel lo hicieran parte de su creación de Alta Costura.

Así, la falda 3/4, creada por Chanel, escandalizó al mundo al exhibir las piernas, un acto inmoral en la Era Victoriana. De modo que, las piernas hacían parte del cuerpo moderno, el talle subió y bajó hasta fijarse en las caderas. En efecto, al crearse el traje socio y ser funcional se crearon las prendas básicas: la chaqueta sastre o el cárdigan, la blusa y la falda, las cuales eran atemporales y se reinterpretaron a través del tiempo, aún en el presente. Este traje fue el antecesor del traje tipo sport, que reinterpretará el Prêt-â-Portêr en su momento.

Además de la silueta y las prendas, los textiles cambiarían. Por ejemplo, en 1910 la mujer empezó a llevar largos jerséis y cárdigan, sobre todo para hacer deporte o viajar. El tejido de punto cambió su contexto y Chanel lo utilizaría para crear sus vestidos y abrigos, brindándole a la mujer prendas mucho más versátiles, de mejor resistencia y a un precio accesible.

Figura 2.

Conjunto de Calle. Chanel (1928). Falda y chaqueta de crepé de lana negro sin forro; suéter de punto blanco.

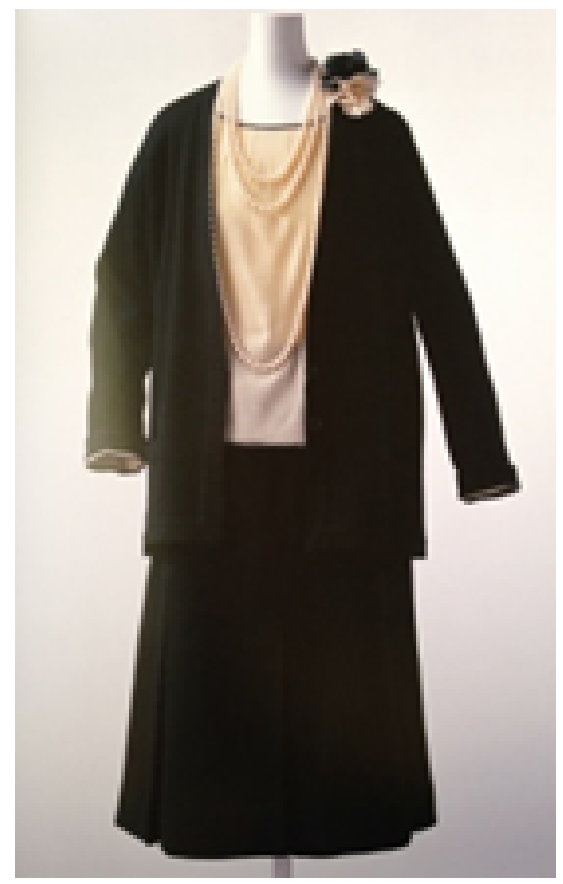

Fuente: Editorial Taschen, 2012. 
Todos estos cambios llegaron a nuestro país cuando se empezó a generar una evolución en las formas de producción. En Colombia desde finales del XIX y comienzos del XX aparecieron de forma explícita procesos de modernización que empezaron a ser vividos profundamente por la población, generando cambios fuertes en la técnica y la economía. Por consiguiente, aparecieron nuevas formas de comunicación y fue muy común ver a grandes detentadores del capital invirtiendo en la fundación de titánicas industrias como Coltejer (en 1908), Cementos Samper (en 1909), Tejidos Obregón (en 1910), Fósforos Olano (en 1909), Cervecería Germania (en 1905), Chocolates Chaves (en 1905), entre otros.

Estos cambios se hicieron evidentes en un episodio que generó mal ambiente en el gobierno de Marco Fidel Suarez, cuando para celebrar el Centenario de la Batalla de Boyacá se encargaron al extranjero uniformes nuevos para el desfile del ejército. Esto provocó un fuerte malestar en la población, en especial en los artesanos. En la protesta de 1919 el ejército disparó contra ellos, causando 15 muertos. Cuando la situación económica desmejoró en el país la más mínima crítica de Laureano Gómez en el Congreso generó la renuncia del presidente Marco Fidel Suarez.

Durante la Primera Guerra Mundial Colombia vivió una situación económica precaria tan fuerte que el mismo presidente se vio obligado a hacer empréstitos, comprometiendo su sueldo y gastos de representación, lo que levantó álgidas denuncias por parte de Laureano Gómez contra el mandatario. Su posición vanguardista tenía como propósito principal acercar a las mujeres a los adelantos materiales, intelectuales y a las promesas de la modernidad.

Otro elemento que trajo más complejidad al período fue que durante la administración de Pedro Nel Ospina iniciaron los desembolsos norteamericanos como indemnización por la pérdida de Panamá y los ajustes al sistema finan- ciero colombiano de la mano de la Misión Kemmerer. Estos acontecimientos fueron un mar de contradicciones, en los que la tan conocida danza de los millones no llegó a toda la población y fue inevitable que los cambios promovidos por la estrella polar, como llamaba Marco Fidel Suárez a Estados Unidos, rompiera todo un sistema de producción, pensamiento y relaciones sociales defendido por un sector de la elite nacional que, aun cuando se resistía al cambio, ya no era posible.

Este fue el momento en que crecieron movimientos sociales como el liderado por Manuel Quintin Lame en el Cauca, el movimiento estudiantil y se fundó el Partido Socialista Revolucionario en 1926. También se dieron un sin número de movimientos huelguísticos, entre los que podemos destacar el liderado por Betsabé Espinal en 1920. Si bien es cierto que estas circunstancias no cambiaron del todo la sociedad colombiana, el proceso se fue dando poco a poco. En cuanto a las condiciones de la mujer, se fue transformando el papel que se le daba y la forma en que se le representaba.

En las elecciones de 1930 ganaron los liberales civilistas, claros adeptos del republicanismo surgido en 1910 con Carlos E. Restrepo, en cuyo gobierno tuvo clara preponderancia el recién elegido presidente de la república Enrique Olaya Herrera. Este punto fue la marca que denota un nuevo periodo. Después de 44 años, Colombia volvió a estar en manos del Partido Liberal, con la presidencia de Enrique Olaya Herrera, hasta 1946. En este período los liberales se preocuparon por promover ciertas políticas en materia laboral y sindical, según los nuevos contextos colombianos, y la mujer empezó a participar en nuevos espacios. Prueba de estos cambios fue el reconocimiento de los derechos económicos de las mujeres casadas con la Ley 28 de 1932.

Los modelos de mujer que existían en nuestro país obedecían a la tradición provinciana, pero, luego, empezaron a popularizarse los de las 
cupletistas, las artistas del cine norteamericano y las mujeres bohemias e independientes, moldeando una mujer trabajadora y vestida para el ámbito oficinista. En la historia de Colombia la mujer había sido mostrada a través del arte por medio de exvotos como forma de reconocimiento social y haber espiritual. Es decir, la mujer era parte integrante de metáforas que querían referenciar el ideal de bondad, perfección y alegorías sobre la unidad de la patria. Las miniaturas se utilizaban para invocar la presencia de la persona amada en el ámbito privado.

De este ambiente artístico hicieron parte las primeras imágenes que aparecieron sobre mujeres en las publicaciones periódicas como la revista Cromos y Fantoches, por ejemplo. En el caso de Cromos, en la primera carátula hizo referencia a la Mantilla Bogotana, cuyo personaje sería usado por su autor Coroliano Leudo en varias obras. A lo largo de finales del siglo XIX y la primera mitad del siglo XX esa mujer recatada representada por la mantilla de Leudo muere. Pero, a pesar de que la mantilla tradicional, conservadora y profundamente religiosa desapareció, surgió una nueva mantilla, en este caso ya no bogotana, sino más bien cosmopolita, progresista y sensual, al lado de las damas caracterizadas por modas extranjeras representadas por las mujeres vestidas con trajes de silueta recta y de cintura holgada. En este período la representación pasó a ser de una mujer que no solo dejaba atrás el espacio privado y piadoso, sino que, también, conquistaba espacios públicos, de consumo y laborales.

No obstante, a pesar de estos cambios, había ciertos sectores que permanecían resistentes a estas transformaciones. Por ejemplo, en 1930 se promovió la liga de la decencia de la mujer para promover la conservación de las buenas costumbres y el vestido honesto. Este movimiento se dio bajo la dirección de la Iglesia Católica y todos los obispos del mundo. Así, se buscó alejar a las niñas de los ejercicios y concursos gimnásticos públicos so pena de expulsarlas de los institutos de enseñanza y no darles comunión. En 1927, el obispo de Santa Rosa de Osos, monseñor Miguel Ángel Builes (uno de los más activos en la época), expidió una carta pastoral sobre el vestido y el pudor de las mujeres. Esto fue una reacción a que la mujer venía en un movimiento contra corriente. En la década de los 20 la mujer había conquistado los lugares públicos y de consumo, entrando en auge la mujer liberada, con apariencia andrógina que disfrutaba el consumo y la vida bohemia.

Esto se profundizó en la década de los 30 con hechos como la creación del Congreso Internacional de la Mujer que promovía el ejercicio físico y las nuevas irrupciones en el arte, como la obra de Débora Arango, insidiosa por sus temas. Entonces, fue en este período en el cual la mujer empezó a reclamar igualdad en cuanto a la vida material. Además, las mujeres empezaron a ingresar a niveles educativos antes vedados para ellas, de modo que la primera mujer aceptada en la Universidad Nacional fue en 1936. Y las carreras que escogían al comienzo eran química, farmacia y bacteriología, aunque, poco a poco, se fueron diversificando hacia otros ámbitos fuera de la salud.

Desde su fundación en 1916 la revista Cromos promovió la cultura física, resaltando la activación de los sentidos y la educación física para fortalecer el cuerpo, aumentar la energía y evitar la pereza. El deporte y el juego eran para la élite y la gimnasia se convirtió en vehículo de disciplina para la masa. Por medio de la gimnasia se buscaba el afinamiento de los sentidos, la percepción, la formación del carácter y la modelación del cuerpo, para construir un ciudadano disciplinado. Además, el cuerpo de la mujer se tonificó y bronceó como símbolo de salud. En 1930 Mary Bagot Stack fundó la Liga Femenina de Salud y Belleza en Inglaterra. En una ocasión reunió 5000 mujeres en una tabla de gimnasia. En la década de los 40 las revistas norteamericanas promovieron Make do and Mend, debido a la escasez bélica, por lo que se promovía reparar y hacer cosas nuevas con los diseños anteriores. La 
estrella principal de la época fue Rita Hayworth por la simulación de un striptease en la película Gilda. Otras grandes actrices fueron Marlene Dietrich y Greta Garbo.

Por último, otro elemento que contribuyó al proceso de cambio que se venía generando de tiempo atrás, con respecto a la participación de la mujer en diversas áreas de la sociedad, fue su cooperación activa en la Segunda Guerra Mundial, tanto en Europa como en EE. UU. En el caso de Colombia este cambio se dio, entre otras cosas, como consecuencia de la industrialización y, también, por la difusión de las ideas socialistas. De esto fue expresión María Cano, quién fue elegida el 10 de mayo de 1925 como Flor del Trabajo por los estudiantes universitarios y su labor en la defensa de los trabajadores es ampliamente reconocida por la historiografía.

\section{Figura 3.}

Señorita Laura Merino y Uribe, enfermera colombiana de la Cruz Roja francesa quien presta sus servicios en Château-Tierry.

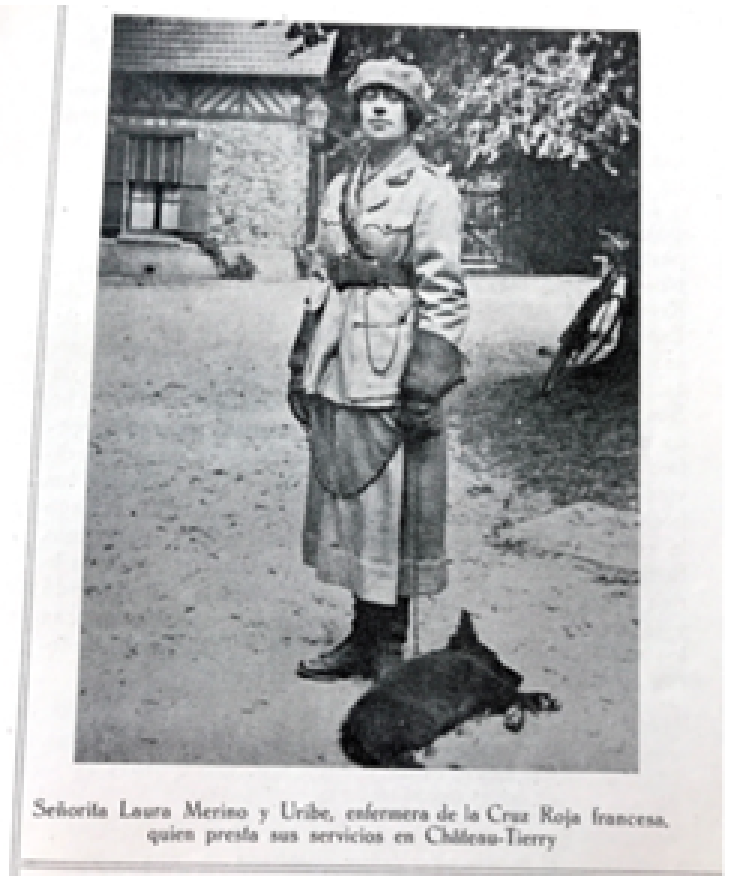

Fuente: Revista Cromos. Número 131. Volumen VI. Septiembre 14, 1918.

\section{Moda}

La alta costura apareció en la gran Exposición Universal de París en 1900. Esta estuvo alojada en el Pavillon de L'Elegance y las modelos de la época fueron en vivo. Eleonora Pose, artista del teatro italiano, y Sarah Bernhardt, actriz de teatro francés, posaron convirtiendo a Paris en el centro de la moda en el mundo. La mujer moderna como modelo a seguir se ubicaba en la sección elegancias de la revista, la cual emergió desde el primer número de la revista como un sueño por alcanzar. En esta sección se describían los vestidos producto de los modistos más representativos de Paris, se daban consejos de Belleza, recetas de cocina, se explica cómo vestir a los niños y se describían las actividades más representativas de la mujer moderna. En esta sección, poco a poco, se evidencia cómo se ponía en práctica el consejo de dejar de lado el Corset, que fue tan dañino para la salud física de las mujeres debido a la popularización de la silueta en forma de $\mathrm{S}$ de 1900 . Además, se ponía en práctica lo que en sus escritos la revista quería aconsejar a la mujer: Un sujeto que se renovaba todo el tiempo, no cansaba y producía encanto, mientras la belleza por sí misma producía aburrimiento.

El lema que se instauró y se profundizó durante la Primera Guerra Mundial fue, en general, menoses más. Vemos, poco a poco, en estas primeras décadas que los elementos decorativos comenzaron a desaparecer y se imponía la uniformidad, la ligereza y lo holgado para garantizar la libertad de movimiento con prendas mucho más pensadas en la funcionalidad. Entonces, el mundo moderno tenía como principal característica el movimiento y la velocidad. Un ejemplo de ello era el diseño de los sombreros, pues el conocido Cloché era ideal no para defender la piel del sol, sino el pelo del desorden producido por el viento.

De esta manera, la moda se convirtió en un bastión fundamental para modelar el cuerpo de la mujer a estas nuevas condiciones, quien 
comenzó a reflejar ese nuevo ideal de belleza relacionado con el deseo y el consumo. La moda empezó a sacar a la mujer del ámbito privado de la casa y la lanzó al ámbito público, a la calle. Entonces, a pesar de que en Europa se encargó de las actividades económicas durante la guerra, al acabarse esta los hombres retomaron su papel, pero las mujeres no quisieron dejar sus espacios ganados. Esto se evidenció en que las faldas fueron mostrando cada vez más pierna y subieron del tobillo a la rodilla. Además, se impulsó el peinado estilo garçonne, adoptado por el ideal de mujer que se difundió en la obra Le garçonne de Victor Marguritte (1922), mostrando una mujer libre, andrógina que no tenía ni cintura, ni busto pronunciado. Se promovía, así, una figura de mujer esbelta, flaca, sin formas protuberantes. La principal representante de este movimiento fue Gabrielle Chanel.

Los nuevos modelos eran sujetos representantes de estos aires de libertad. Así, apareció la Flapper girl, mujer versátil que se movía al ritmo del aleteo de una mariposa (= to flap). Esta mujer era descrita en el cuento Bernice Bobs Her Hair de Francis Scott Fitzgerald y protagonizada en 1929 por Louis Brooks en la película La caja de pandora.

En la década de los 20 las fotografías mostraban la generalización de mujeres liberadas y bohemias, representadas en las jóvenes verbeneras o cupletistas, divas intérpretes del género del Cuplé, el cual había surgido del cuplet político liberal desarrollado al lado del teatro. Eran mujeres relacionadas con la tertulia, el bar y la vida nocturna. De esto fue principal representante Raquel Meller, famosa por interpretar el Pasodoble El Relicario compuesto por José Padilla. De la misma época y representando este estilo de vida, pero desde el otro lado del atlántico, en esa misma década aparecieron las flappers norteamericanas. Estas chicas liberadas de cuerpo andrógino que conquistaban los espacios de la vida nocturna al ritmo del Charleston, blues, etc.
La caída de la bolsa de valores de Wall Street el 29 de octubre de 1929 trajo consecuencias en varios aspectos. Por este evento la mayoría de los países cerraron sus fronteras para defender su economía. En este caso, París se cerró a EE. UU., y la ciudad de la Luz siguió manteniéndose como vanguardia en materia de moda. En este período se pasó de la elegancia al utilitarismo. Se generalizó la simpleza, la comodidad y el enfoque práctico. Las prendas se empezaron a combinar entre sí para poder adaptarlas a diversas ocasiones y las mujeres comenzaron a conquistar los escenarios de las oficinas con mayor fuerza, lo que generó que su vestimenta se inclinara a esta inspiración.

Luego de los 30 las mujeres comenzaron a conquistar nuevos espacios, ya no solo los relacionados con la diversión en el ámbito público, sino en el ambiente laboral y, en Colombia, la revista Cromos fue testigo de esto. Vemos como se promovía la capacitación de las mujeres en actividades como las operadoras de teléfonos, trabajadoras en fábricas europeas durante la guerra y en labores mecanográficas. Esto hizo que las mujeres no solamente se fueran acercando a las fuentes del progreso, sino que fueran artífices del progreso mismo, haciendo parte de la cadena desde la producción y no solo desde el consumo, como había sucedido en la década anterior.

En 1940 entró en vigor la Limitación de suministros en Alemania y en Inglaterra se creó el Utility Clothing Scheme, en el cual se escogieron 32 modelos que se realizaron en masa. En EE. UU. en 1941 se hizo lo mismo con el General Limitation Order L-85. Esto hizo que el estilo se orientara al sastre estilo militar. En 1942 apareció el cartel y la canción de Rosie la remachadora, con lo cual se elogiaba el trabajo de las mujeres en las fábricas bajo el slogan; We can do it! 


\section{Mujer y Moda, el paso a la Modernidad}

El cuerpo de la mujer bogotana no era distinto al cuerpo de la mujer civilizada, ya que el cuerpo femenino era universal. En efecto, el vestido era un elemento tangible que se entendía como un signo lingüístico, un elemento comunicador, pero que también podía crear ciertos patrones de distinción y transformación corpórea. El vestido, al generar una transformación corpórea, se configuraba por medio de estructuras, como lo fueron el polisón (Laver, 2017) y el corsé, los cuales fueron piezas creadoras del artificio $^{1}$ de finales del siglo XIX.

\section{Figura 4.}

Fabricante desconocido. Cubrecorsé, calzón y polisón. 1880-1910. Algodón cosido a máquina y calado a mano. Reg. 234, 235, 236, 226.

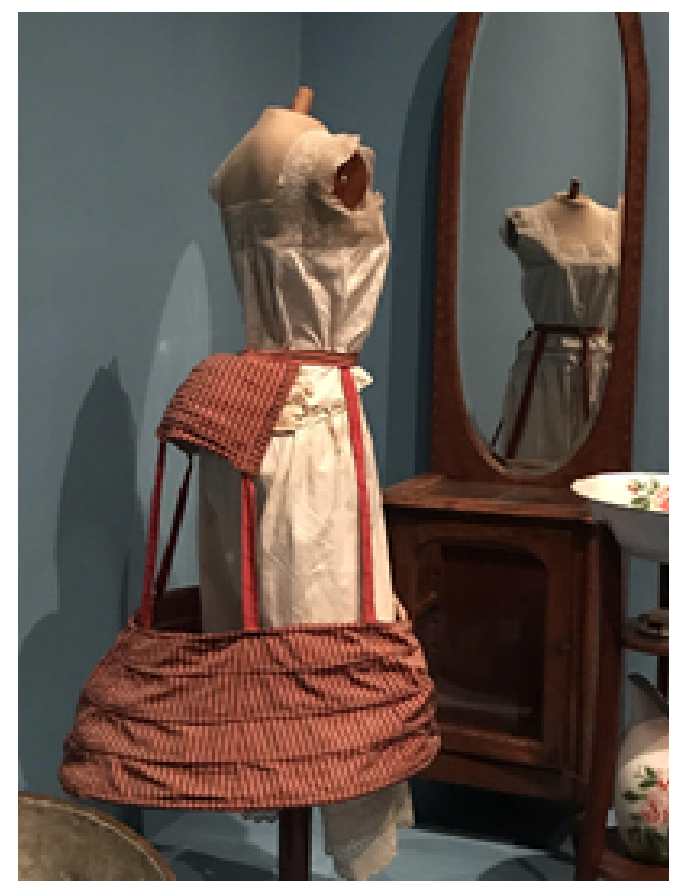

Fuente: Colección Museo del Siglo XIX. Fondo Cultural Cafetero. Donado por Juanita de Solano (Cubrecorsé). Fotografía Angela Ramos López (2018).

${ }^{1}$ Concepto que hace referencia a la ostentación creada por el Antiguo Régimen durante todo el siglo XVIII durante la época del Barroco y el Rococó, especialmente, y que, a pesar de la Revolución Francesa de 1789 y la transición que hubo durante la época del Directorio y el Primer Imperio, se transformó y creó un impacto en las sociedades burguesas europeas y latinoamericanas.
Por lo tanto, el polisón cumplía con la misión de sostener el volumen de la parte superior de la falda. Podía ser de diversos materiales, entre ellos crin engomado, guata y paja, e incluso algunos improvisados, creados a partir de papel periódico arrugado. Podrían estar construidos en acero forrado, aros completos alrededor o medios aros dependiendo del diseño de cada atuendo. Se puede observar que, en la figura 4, el polisón fue confeccionado de manera empírica, quizás por alguna modista, quien cosió esta pieza a máquina y a mano, tratando de simular un modelo de polisón tomado de alguna revista europea.

Cabe mencionar que el polisón en Europa fue creado en el año de 1870, cuando la moda se volvió más suave y delicada, con colores pastel y guarniciones livianas, lo cual se materializó en el polisón y las famosas enaguas. Se llevaban los escotes cuadrados y las mangas tres cuartos con puños de encaje. Hacia 1875 los colores se intensificaron, a la vez que surgía una línea del cuerpo más estilizada, suavemente ajustado, cintura y cadera mucho más definidas (Kindersley, 2013).

Estas clases privilegiadas, para demostrar su pertenencia a la burguesía bogotana, requirieron varios tipos de vestimentas, que estaban destinadas a cumplir con una ocasión de uso. Por lo tanto, las mujeres de la élite debían reunir un número amplio de ajuares, sus armarios debían estar llenos de vestidos con diferentes estilos y tendencias modernas. Estos fueron importados por las primeras familias que tuvieron la oportunidad de viajar al extranjero, como la familia del señor Alberto Carrizosa Valenzuela y el señor Fernando Carrizosa Valenzuela (Ortega, 2018).

Estos trajes fueron adquiridos por estas familias a través de sus viajes al continente europeo, o por medio de encargos a casas de moda europeas, cuyos agentes comerciales las traían al país. De igual manera, hay que tener en cuenta que, a partir de las publicaciones de revistas de moda, fueran extranjeras o nacionales, se comenzó a 
divisar las tendencias europeas y norteamericanas del momento y, por ello, las mujeres de la burguesía querían estar a la vanguardia y sentirse que pertenecían a una sociedad civilizada.

De esta manera, la gran mayoría de vestidos eran fabricados en tafetán y en seda, sobretodo en sedas brocadas, ya que este tipo de materiales comunicaban opulencia, lujo, y, por ende, jerarquización y distinción social, lo cual se evidencia en el atuendo de la figura 5, el cual está fabricado en brocado de satín, azabaches y pedrería cosidos a máquina y a mano. Toda una obra de Alta Costura, un vestido que quizás fue importado.

\section{Figura 5.}

Mme. Delannoy. Vestido de Luto. Ca. 1890. Brocado de satín, azabaches y pedrería cosidos a máquina y a mano. Reg.7.

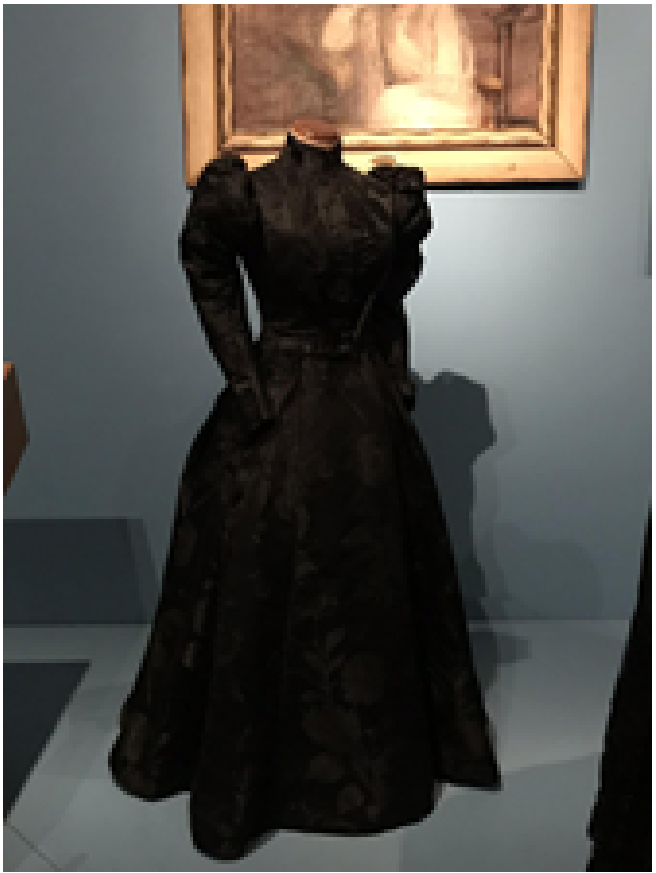

Fuente: Colección Museo del Siglo XIX. Fondo Cultural Cafetero. Donado por María Carrizosa de Umaña. Fotografía Angela Ramos López (2018).

2 "La sociedad victoriana se regía por severos rituales sociales y complejos códigos de etiqueta, la adherencia a los cuales denotaba sentido del decoro, el atributo más preciado. Todo ello era resultado de la influencia de la reina Victoria quien, tras la muerte de su esposo el príncipe Alberto en 1861, guardó luto toda su vida. El luto por entonces se dividía en cuatro fases, conocidas como luto completo, luto segundo, ordinario y, por último, medio luto". Origen del concepto Ritualismo en las costumbres vestimentarias.
Podríamos decir que el deseo de exhibir una apariencia elegante, suntuosa y acorde con las demandas de etiqueta y protocolo que exigía un evento tanto social como familiar hizo que la moda se vinculara de una manera estrecha al hecho de ser mujer. Algunos manuales de comportamiento aseguraban que una mujer debía tener gracia y dignidad a la hora de vestir, en este caso con el vestido de Luto, que sería una tendencia estética durante toda la Era Victoriana (Mackenzie, 2010) en Inglaterra y en la gran parte de Europa.

En este caso, el vestido de Luto tendría una importancia global, ya que nació a partir de la muerte del Príncipe Alberto de Sajonia, quien fue el esposo de la Reina Victoria. A raíz de su pérdida, el vestido de Luto se convirtió en una extensión del sufrimiento de la reina, fue el significado tangible de su dolor y, como consecuencia, el vestido se convirtió en una extensión de sus sentimientos. Este vestido sería un símbolo alrededor del mundo, el cual trascendería todas las fronteras del mundo occidental. Su utilización tendría un carácter relevante, no solo para utilizarlo en momentos de viudez, sino, también, en caso de pérdidas familiares o para guardar el debido recato en algunas ocasiones como lo menciona Staffe: "El traje, así entendido, revela no solamente el buen gusto, sino la rectitud del juicio" (Staffe, 1876, p. 182). En otro apartado nos dice: "El vestido pulcro y atildado denota costumbres distinguidas, cierta delicadeza, elegancia natural, y por eso da buena idea de quien lo lleva" (Staffe, 1876, p. 182).

Staffe expone, a través de estos enunciados, que las costumbres distinguidas estaban ligadas a las normas y expectativas culturales, que podían ser impuestas en la presentación del Yo en la cotidianidad, pero esta se veía reflejada por medio del cuerpo-vestido porque creaban un vínculo tanto íntimo como social. Así, se generaba una integración sinérgica en la cual la moda se hacía 
presente en la sistematización de comportamientos, los cuales eran significativos y expresaban los valores característicos de una época determinada (Squicciarino, 1986).

\section{Figura 6.}

Artículo Cromos de agosto 12, 1919. Sección Elegancias. Tendencias orientales. Madame Valmore.

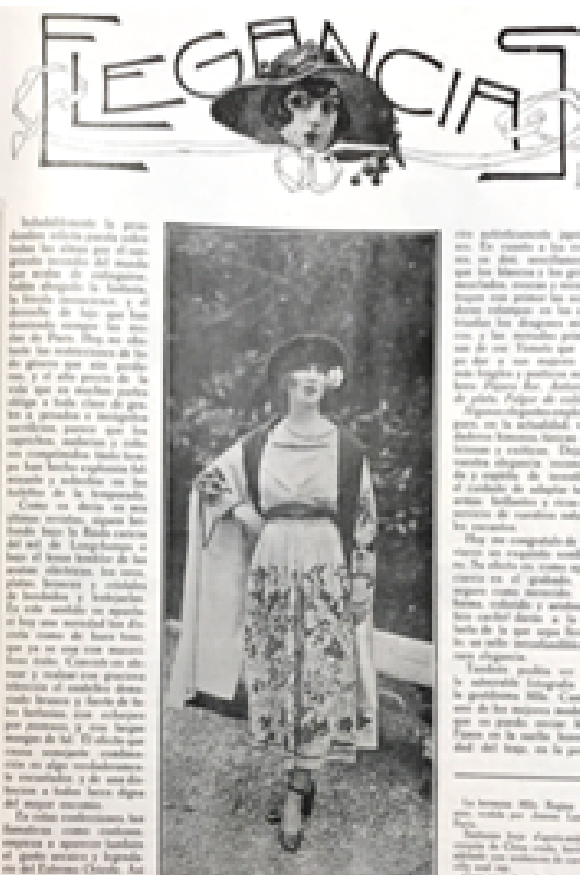

Fuente: Revista Cromos. No. 181. Volumen VIII. Septiembre 27, 1919.

La revista Cromos en su sección Elegancias relataba las tendencias que, gracias a sus corresponsales, eran enviadas desde París y Nueva York. En el caso de la imagen 6, a Madame Valmore, al parecer, le agradaba el cambio de la silueta, en efecto, ella lo describía como una novedad discreta con buen tono y, por ende, exitoso. Aseguraba que era una combinación encantadora y que la mayoría de las mujeres en París lo ba para ir a la Opera y para pasearse en los Campos Elíseos, aunque mencionaba que era de gusto arcaico y legendario del Extremo Oriente. Asimismo, Valmore describía que le impactaba la honestidad del traje, gracias a la precisión de los estampados y la riqueza de dibujo en los mismos, compaginada con la suavidad griega de los tonos.
Así, lo clásico volvió a estar de moda. Tanto la silueta griega como la oriental se encontraban enmarcadas en una distinción de clase, de prestigio visual. No había necesidad alguna de exhibir más allá de lo que la mujer debía mostrar: Figuras angelicales que proyectaban elegancia y distinción. El corsé no era más el protagonista, sino los volúmenes y las líneas rectas del cuerpo, aunque la cintura se marcaba en un entalle muy sutil, gracias a un canesú o un ceñidor.

De este modo, el estilo neoimperio también se tomó el mundo de la moda, pues el neoclásico que se reinterpretó del mundo grecorromano en el Primer Imperio volvió como ese estilo neo, nuevo, con algunas modificaciones. Es importante aclarar que lo clásico, como lo griego y lo romano a través de la moda, se reinventó, fue reinterpretando y, por ello, se debe hacer una prudente conceptualización de los términos aquí escritos.

El estilo neoimperio también nació a finales de 1910, ya que la silueta se suavizó y se retomó el corte imperio en los trajes femeninos. El polisón fue abolido porque las formas del cuerpo-vestido debían verse naturales y simples, claro que sin perder la elegancia y la distinción. Este tipo de atuendos, fueron los denominados tea gowns, o vestidos de tarde por los ingleses. Por lo tanto, este estilo revivió las antiguas estéticas y expuso de manera anticipada, quizás, la liberación total del cuerpo de la mujer que vendría en los próximos años: creaciones en materiales suaves, dóciles y flexibles que les brindarían a estos cuerpos-vestidos un fácil movimiento y relativa comodidad.

Entonces, la figura femenina rompió con los esquemas. Es cierto que el estilo neoimperio y el orientalismo fueron levemente aceptados dentro de las sociedades burguesas, pero al llegar la funcionalidad de la silueta al cuerpo femenino transgredió el lenguaje semiótico del vestido y del cuerpo per se. 
La moda y modernidad son dos palabras que se conectan la una con la otra. La moda moderna de los años 20 se convirtió en la tendencia dominante, caracterizada por las líneas sencillas, silueta andrógina y el renuncio al adorno extravagante y superfluo (Mackenzie, 2010). Es decir, se convirtió en una moda transgresora, capaz de cambiar el cuerpo femenino y, por qué no decirlo, cambiar la mentalidad femenina por completo, imponiendo la silueta tipo tabla o cuadrada, imagen juvenil y aniñada, el busto plano, torso cuadrado y caderas no pronunciadas. Muchos decían que la imagen femenina se había masculinizado, pero en realidad, era el miedo a que la mujer pudiera dejar de depender completamente del hombre.

\section{Figura 6.}

Señoritas Emilia y Blanca Nieves Ramos. Parque de la Independencia.

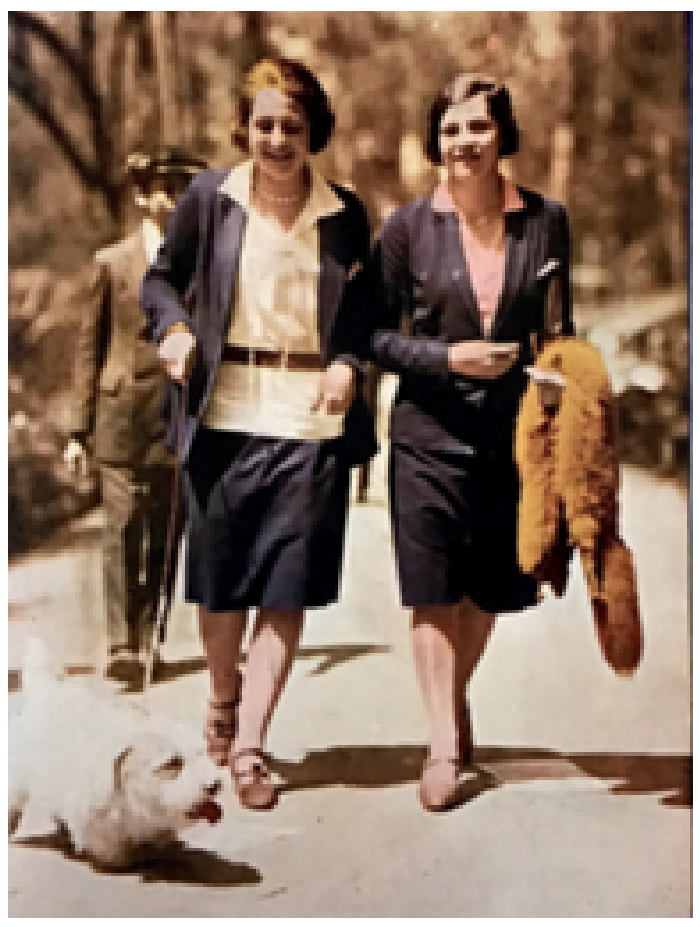

Fuente: Fotografía para la portada de la revista Cromos, Vol. XXVI. No. 638. Diciembre 8, 1928.

\section{Conclusiones}

La historia cultural se centra en los hechos históricos que suceden en los diversos grupos de la sociedad (Burke, 2000), en los cuales existen analogías entre el pensamiento individual y el del grupo. Este pensamiento se nutre de la influencia de los colectivos a los que los individuos pertenecen, para generar, así, una identidad cultural. Esta, a su vez, se manifiesta a partir de la cultura visual, como base principal de la construcción de identidad por medio de la representación visual (Hernández, 2005), que constituye una serie de posiciones y discursos en los que las actitudes, las creencias y los valores hacen parte de una significación cultural.

Es de esta manera que la cultura visual emerge desde múltiples disciplinas de estudios, tales como la semiología, la sociología, los estudios culturales y los feministas, que son la base de la construcción de imaginarios colectivos y de las sociedades que crean una genealogía de la cultura visual (Hernández, 2005), la cual se convierte en un atributo de una sociedad específica o con base de un estrato de esta. Esta genealogía de la cultura visual se construye a partir de la creación de identidades, que hace parte del estudio de las prácticas culturales de la mirada y la visualidad que se define a partir del acto social. Así, el sentido de lo que vemos es la respuesta a la observación visual a un nivel más profundo y analítico, transformándose como el arte de ver.

En este orden de ideas, la percepción que nosotros tenemos de las imágenes está sujeta al cambio cultural, a la vez que esta expresa un cambio de experiencia del cuerpo, por lo que la historia cultural de la imagen refleja, también, en una análoga historia cultural del cuerpo (Belting, 2007). En efecto, las propias imágenes pueden considerarse como medios del conocimiento que se manifiestan como textos, ya que la imagen reclama un nuevo contenido conceptual, en el que se establece que, al carecer de un cuerpo, requiere de un medio por el cual corporizarse, a través 
de un enfoque humano y un artefacto técnico, en el que la imagen se pueda fundamentar antropológicamente mediante la escenificación en un medio de representación como lo es el acto de la percepción simbólica (Belting, 2007).

Esa percepción simbólica hace parte de las normas y expectativas culturales que se imponen en la presentación del Yo, en este caso, de lo femenino en la vida cotidiana de 1886 a 1945, a través de la moda por medio del vestido y el cuerpo, como un mecanismo individual en el cual estos elementos se extienden a partir de un vínculo que construye una experiencia tanto íntima como social, en la que se presenta la codificación de comportamientos significativos que expresan los valores característicos de una época determinada (Squicciarino, 1986). A su vez plantea la relación que existe entre el individuo, el cuerpo, las modas y la cultura del momento.

Ahora bien, el género se denota como el conocimiento que establece los significados de las diferencias corporales entre lo masculino y lo femenino, pero que, también, puede surgir a partir de la connotación jerárquica entre lo dominante y lo subordinado que, dentro del marco de las nuevas burguesías, la mujer es un claro ejemplo de esta significación entre estas dicotomías. De acuerdo con Scott, el estudio de género ofrece una buena manera de pensar la historia sobre la forma en que se han constituido las jerarquías de la diferencia, tanto inclusiones como exclusiones. Siendo esto un planteamiento para debatir acerca de la ideología de la domesticidad durante el siglo XIX y la historia de las reivindicaciones de las mujeres en cuanto al derecho del control sobre sus cuerpos, los cuales fueron estudios aplicados durante la década de los años 80 por algunas feministas y que pueden ser incluidos a partir del objeto de estudio de este artículo. De este modo, podría plantearse una discusión en la que se establezca la importancia de la representación y la relación existente entre las maneras de ver y ser vistos, y cómo ello puede generar una reflexión acerca de las intersecciones que existen entre las mujeres y los hombres.
Asimismo, a lo largo de este recorrido nos pudimos dar cuenta que la moda fue parte fundamental de los cambios que experimentó el lugar que fue buscando la mujer dentro de la sociedad en la primera mitad del siglo XX. Las mujeres en nuestro país por medio de nuevas siluetas definidas por nuevas prendas y peinados fueron ubicándose en espacios públicos, ejerciendo actividades y actitudes liberales y modernas. Estas circunstancias hicieron que las mujeres empezaran a cambiar sus actitudes y que valores como el movimiento, la versatilidad, el cambio e intelectualidad ingresaran en sus objetivos.

En otras palabras, a través de este artículo pudimos evidenciar que las dicotomías cuerpo-vestido no existen, y que estos dos objetos pueden significar, por medio de la representación visual y el acto de ver, el papel performativo y distintivo que se crea por medio del individuo en unidad. La flapper o garçonne no sería llamada así sino fuera posible la construcción de la estética, pelo corto, falda arriba de la rodilla, silueta tipo tabla. Esos elementos permiten que el cuerpo y el vestido estén en completa conjunción, y que den como resultado una completa lectura de dicha imagen que representa un manifiesto individual y colectivo.

Tanto el género como la moda se constituyen a partir de un entorno cultural en el cual se establecen ciertas estéticas que permiten vincular al individuo a ser partícipe de unas transformaciones que responden a unos códigos establecidos, pero que, a su vez, pueden ser transgredidos al depender de un tiempo y un espacio como respuesta a los cambios que nacen en la sociedad. 


\section{Referencias}

Archivo Revista Cromos. (1916-1930). Biblioteca Nacional de Colombia.

Archivo Revista Fantoches. (1926-1927). Biblioteca Nacional de Colombia.

Barthes, R. (1993). La Aventura Semiológica. Paidós Editorial.

Belting, H. (2007). Antropología de la Imagen. Katz Editores. Buenos Aires. Argentina.

Borja, J. (2011). Historia de la vida privada en Colombia. Tomo II. Editorial. Taurus.

Bourdieu, P. (1998). La distinción. Editorial Taurus.

Burke, P. (2005). Visto y no visto. El uso de la imagen como documento histórico. Crítica.

Burke, P. (2000). Formas de Historia Cultural. Alianza Editorial.

Castro Gómez, S. (2009). Tejidos Oníricos. Movilidad Capitalismo y biopolitica en Bogotá (1910-1930). Instituto Pensar, Centro Editorial Javeriano.

Chartier, R. (1996). Escribir las prácticas. Ed. Manantial.

Chartier, R. (2008). Escuchar a los muertos con los ojos. Lección inaugural en el Collège de France. Katz Editores.

Duque, C. (2010). Judith Butler y la teoría de la performatividad de género. Revista de Educación y Pensamiento, 17, pp. 85-95. https://dialnet.unirioja.es/descarga/articulo/4040396.pdf
Edición Cromos 90 años. (mayo 15 de 2006). No. 4.602.

Edición Cromos 95 años. (junio 17 de 2011). No. 4.812 .

Entwistle, J. (2002). El cuerpo y la moda: una visión sociológica. Paidós.

Exposición del Museo Nacional, El Museo en el museo, un lugar entre el XIX y el XX (13 de abril al 24 de junio de 2018).

Gómez Cely, A. (13 de abril al 24 de junio de 2018). Capítulo 4: «Los Modernos del 900. Los lugares de lo público y lo privado», $\mathrm{Ca}-$ tálogo de la Exposición del Museo Nacional, El Museo en el museo, un lugar entre el XIX y el $X X$.

Hernández, F. (2005). ¿De qué hablamos cuando hablamos de cultura visual? Educa o \& Realidade, 30, 9-34. http://www.redalyc.org/articulo.oa?id=317227042017

Kindersley, D. (2013). MODA, Historia y Estilos. 1914-1918, Mujeres en Guerra. Traducción Español.

Laver, J. (2017). Breve historia del traje y la moda. Decimotercera Edición. Grandes Temas Cátedra.

Mackenzie, M. (2010). Ismos para entender la moda. Lengua Castellana. Turner.

Olivos Lombana, A. (2018). Prostitución y "mujeres públicas” en Bogotá. 1886-1930. Pontificia Universidad Javeriana.

Pedraza Gómez, Z. (1990). En cuerpo y alma: Visiones del progreso y de la felicidad. Universidad de los Andes. 
Rose, S. (2012). ¿Qué es Historia de género? Alianza Editorial.

Scott Wallach, J. (2008). Género e Historia. Universidad Autónoma de México-Fondo de Cultura Económica de México.

Soral, A. (1998). La creación de la moda, cómo entender, dirigir y crear la moda. Escuela de Diseño Arturo Tejada Cano.

Sposito, S. (2016). Historia de la Moda. Promopress.

Squicciarino, N. (1986). El vestido habla: consideraciones psico-sociológicas sobre la indumentaria. Cátedra.

Taschen. (2012). Moda, una historia desde el siglo XVIII al siglo XX, Tomo II: Siglo XX.

Toro, M. V. (1995). Las mujeres en la historia de Colombia: Mujeres y cultura. T. 3 (Vol. 3). Ed. Norma.

Traversa, O. (1997). Cuerpos de papel. Figuraciones del cuerpo en la prensa. 1918-1940. Editorial Gedisa.

Tirado Mejía, A. (1989). Nueva Historia de Colombia. Editorial Planeta.

Vilches, L. (1987). Teoría de la imagen periodística. Paidós. 